ISSN 1518-3483

Licenciado sob uma Licença Creative Commons

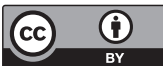

\title{
Professor-pesquisador: concepções e práticas de mestres que atuam na educação básica
}

\section{Teacher-researcher: conceptions and practices of master professors who work in elementary schools}

\author{
Rita Buzzi Rausch
}

Doutora em Educação pela Unicamp, Campinas, professora do Programa de Pós-Graduação em Educação da Universidade Regional de Blumenau (FURB), Blumenau, SC - Brasil, e-mail: rausch@furb.br

\section{Resumo}

Embora na formação de professores busca-se formar o professor-pesquisador, e a pesquisa seja reconhecida como atividade fundamental, o seu uso e significado geram polêmicas. Além das licenciaturas, a formação do professor-pesquisador é intenção também de diferentes programas de pós-graduação stricto sensu no país. Neste sentido, buscamos investigar: quais as concepções e práticas de pesquisa de professores mestres que atuam na docência na educação básica? O objetivo foi conhecer as concepções e práticas em pesquisa de professores mestres. De abordagem qualitativa, realizamos entrevista semiestruturada com oito mestres docentes. Quanto à concepção de professor-pesquisador identificamos três vertentes: a) o profissional que se mantém atualizado; b) o profissional que prioriza a pesquisa em detrimento do ensino; 
c) o profissional que investiga sua prática docente. Nessa última concepção, porém, não percebemos o entendimento de pesquisa como um processo sistematizado, no sentido de se fazer ciência relacionada à docência. A maioria dos professores demonstrou interesse e habilidade em realizar pesquisas na escola, porém manifestou impossibilidades graças a fatores relacionados à estrutura física, falta de tempo, baixa remuneração e ao pouco apoio por parte dos gestores. A maioria destacou que o mestrado contribuiu com sua formação de professor-pesquisador. Este estudo permitiu analisar que na literatura educacional, há ênfase na necessidade de formar o professor-pesquisador. Entretanto, muitas vezes não se discute a trajetória de formação dos professores, as condições de trabalho e de carreira e os recursos financeiros e de infraestrutura necessários para o professor conseguir realizar pesquisas nas escolas.

Palavras-chave: Educação básica. Professor-pesquisador. Professores mestres.

\section{Abstract}

Although teacher education seeks to form a teacher-researcher and the research being recognized as a fundamental activity, its use and meaning has generated controversy. In this sense, we have investigated: which are the conceptions and practices of stricto-sensu research master degree professors who teach at elementary schools? The objective was to identify the concepts and practices in search of master teachers. This qualitative study was conducted in semistructured interviews with eight master professors. As for the design of teacher-researcher we have identified three aspects: $a$ ) the professional who keeps up-to-date, $b$ ) the professional that prioritizes research over teaching, c) the professional who investigates his/her own teaching practice. However, we have not noticed the understanding of research as a systematic process, in order to do science related to teaching. Most teachers demonstrated interest and ability in conducting research in the school, however, they have expressed difficulties due to factors related to the physical structure, lack of time, low salary and poor support from the school managers. They have noticed that the master's contributed in his/her training as a teacherresearcher. This study allowed us to analyze the educational literature which gives an emphasis on the need to train the teacher-researcher. However, often it is not discussed the history of the professors' training, working conditions, career, the financial resources and also the infrastructure necessary for the teacher to be able to conduct research in the schools.

Keywords: Elementary school. Teacher-researcher. Master professors. 


\section{Introdução}

É comum ouvirmos falar e ler acerca da necessidade de o professor ser reflexivo e pesquisador na contemporaneidade. Essa perspectiva prioriza a reflexão e a pesquisa como elementos necessários à formação docente e desloca parte importante dessa formação para o contexto da escola, da docência. Conforme destaca Silva (2008), tal proposta reforça a reflexão docente sobre a prática e os sentidos que essa reflexão possa provocar na ressignificação da experiência docente e, consequentemente, da prática educativa. O professor, a partir da reflexão sobre sua própria prática, estabelece novas possibilidades de ação sobre sua docência, surgindo, a partir de tal premissa, a epistemologia da prática, que subjazem as teorias do professor-reflexivo-pesquisador.

Portanto, a ideia da importância da pesquisa e da reflexividade no trabalho do professor não é recente. Lüdke (2010), no programa de pesquisa que coordena, vem investigando, junto ao seu grupo de pesquisadores o lugar da pesquisa na formação e no trabalho do professor da educação básica. Diante dos estudos já realizados, o programa constatou que alguns professores estão realizando pesquisas em escolas de educação básica da rede pública, o que confirma a possibilidade de sua realização neste contexto. Destacam que o tipo de atividades consideradas como pesquisa "[...] vão da simples organização de uma feira de ciências, ou o aprofundamento de um tema de estudo por um grupo de professores, até o desenvolvimento de trabalhos bastante sofisticados, com publicação em revistas internacionais" (LÜDKE, 2010, p. 264).

A disparidade de exemplos emitidos como pesquisa fez os pesquisadores do programa anteriormente mencionado se indagarem acerca do conceito de pesquisa dos professores investigados. E na busca de respostas para tal indagação, obtiveram como resposta uma definição acadêmica de pesquisa, entretanto seguida do argumento de que não era essa modalidade de pesquisa de que necessitavam na escola. Isso denota certo distanciamento entre a pesquisa realizada na academia e aquela aplicada pelos professores nas escolas de educação básica. 
Nessa direção, Zeichner (2009) também se questiona acerca dos tipos de pesquisa que são mais próximos da realidade dos professores, porém sem perder de vista certos requisitos básicos na sua caracterização. Esse autor aponta a formação como fundamental na busca da credibilidade da pesquisa. Entretanto Lüdke (2010) destaca que os professores, de maneira geral, declaram-se muito insatisfeitos em relação à formação para a pesquisa recebida em seus cursos de licenciatura.

No Brasil, infelizmente, a maioria dos professores tem contato com a pesquisa em sua completude somente em cursos de pós-graduação, mais especificamente em nível stricto sensu. É a partir do mestrado que os professores necessitam realizar uma pesquisa de autoria própria e geralmente se formam como pesquisadores. Nesse sentido, realizamos uma pesquisa que investigou: quais as concepções e práticas de pesquisa dos professores que possuem mestrado e atuam como docentes na educação básica?

$\mathrm{Na}$ busca de respostas à questão-problema formulada, definimos como objetivo geral conhecer as concepções e práticas em pesquisa de professores mestres que atuam na docência na educação básica da Rede Municipal de Ensino de Blumenau. Como objetivos específicos elencamos: identificar as concepções de professores mestres acerca do conceito "professor-pesquisador"; identificar se os professores mestres se consideram professores-pesquisadores destacando, em sua prática docente, indicadores que permitam caracterizá-los como tal e analisar a influência do mestrado ao desenvolvimento de uma postura investigativa na docência da educação básica.

O presente artigo está estruturado em quatro partes, iniciando com esta introdução em que trazemos a abordagem e a justificativa do problema, a questão de pesquisa e seus objetivos. A segunda parte trata dos aspectos metodológicos da pesquisa, baseados na literatura específica, em que explicamos os procedimentos adotados na investigação. A terceira parte apresenta a descrição dos dados obtidos nas entrevistas, que, precedida da análise de conteúdo, apresenta os resultados. Por fim, na quarta e última parte fazemos algumas considerações e recomendações ao estudo realizado. 


\section{Procedimentos metodológicos}

Este estudo possui uma abordagem qualitativa. Os sujeitos envolvidos nesta pesquisa foram os professores mestres que atuavam na educação básica da rede municipal de Blumenau no segundo semestre de 2010. A partir de um diagnóstico junto à Secretaria Municipal de Educação do município, constatamos a quantidade de professores com titulação de mestrado atuando nos níveis de educação infantil e ensino fundamental em diferentes instituições de ensino.

Quanto aos procedimentos, após levantamento dos nomes e escolas em que os professores mestres atuavam, ligamos para cada um deles, solicitando espaço para um encontro, estipulado por eles dentro de suas disponibilidades, para realizar uma entrevista. De dez professores com mestrado atuando em sala no momento da recolha de dados, conforme informações recebidas pela Secretaria Municipal de Educação, oito concordaram em participar como sujeitos da pesquisa. A entrevista ocorreu dentro das instituições de ensino municipais ou nas dependências da FURB, nos casos em que o professor tinha algum vínculo com a instituição ou assim preferisse.

Para registrar os dados obtidos na entrevista, utilizamos a gravação direta, por meio de um aparelho de MP4, para posterior transcrição e análise. A pesquisadora entrevistou cada professor pessoalmente e individualmente, de forma clara e objetiva, a partir de um tópico guia envolvendo as seguintes temáticas: a) Concepção de professor-pesquisador; b) Se os professores se consideram professores-pesquisadores; c) Indicadores de sua atuação docente que os caracterizam como professores pesquisadores; d) $\mathrm{O}$ mestrado como propulsor de uma postura investigativa da docência. O tópico guia foi elaborado com a finalidade de nortear e focar a entrevista para as questões centrais da pesquisa.

Após transcrição dos dados, procedemos à análise de conteúdo, respeitando as suas diferentes fases cronológicas conforme destaca Bardin (1977): primeiro a pré-análise; segundo a exploração do material; terceiro o tratamento dos resultados, a interferência e a interpretação. Da primeira 
fase, são fundamentais a leitura, a escolha dos documentos e a formulação de hipóteses e dos objetivos. A segunda é a fase da "administração sistemática das decisões tomadas. [...] Essa fase, longa e fastidiosa, consiste essencialmente de operações de codificação, desconto ou enumeração, em função de regras previamente formuladas" (BARDIN, 1977, p. 101). Com ênfase para a última, a autora destaca que é uma afirmação provisória, a qual se proporá verificar, recorrendo aos procedimentos de análise.

Neste processo de análise, o fundamental foi relacionar os dados à teoria em estudo. Foram entrevistados oito professores, individualmente, cujas identidades permanecem em sigilo, doravante denominadas apenas como Professor 1, Professor 2, e assim por diante.

\section{Descrição e análise dos dados}

\section{Concepções de professor-pesquisador de professores mestres}

Observamos que não existe uma concepção formada e bem definida a respeito do que é um professor-pesquisador, mesmo entre os professores-mestres investigados. Percebemos, nas respostas, concepções com diferentes significações e não muito precisas. Ao analisar-se a concepção que cada um tem sobre o que é professor-pesquisador, identificamos diferentes grupos.

Dentre os oito entrevistados, dois demonstraram entender que o professor de sala de aula torna-se um professor-pesquisador por meio de uma postura investigativa e reflexiva de sua prática e da atividade docente como um todo. Apresentamos a seguir breves episódios das transcrições das entrevistas realizadas que evidenciam tal afirmação:

Professor 1: Eu penso que professor-pesquisador é aquele que consegue pesquisar a sua própria ação e sua própria prática e talvez a dos colegas também. 
Professor 8: Para mim, professor pesquisador é aquele que faz da sala de aula o seu universo de pesquisa. [...] Aí vai do interesse da pesquisa dele, se ele quer pesquisar a forma como os alunos aprendem, se ele quer focar o olhar dele sobre como ele está atuando, sobre o processo de ensino, sobre o processo de aprendizagem.

As definições apresentadas pelos professores anteriormente se aproximam da ideia de Esteban e Zaccur (2002), quando mencionam que os professores-pesquisadores são os que produzem conhecimentos sobre a sua docência, de modo que o desenvolvimento dessas atitudes e capacidades permite reconstruir saberes, articular conhecimentos teóricos e práticos e produzir mudanças no seu cotidiano. Diante das dificuldades do dia a dia, o professor que busca relacionar a prática com a teoria terá mais subsídios para solucionar as situações problemas que vierem a surgir no decorrer do ensino/aprendizagem. Entretanto, nossa preocupação recai por não percebermos em suas respostas o entendimento de pesquisa como um processo sistematizado, no sentido de se fazer ciência relacionada à docência.

É arriscado e simplificador aceitarmos para a pesquisa feita na escola básica uma classificação exclusiva, pois ela poderia trazer consigo uma conotação restritiva e limitadora, com prejuízo para o próprio conceito de pesquisa e para sua função de produção de conhecimento sobre problemas que pedem solução (LÜDKE, 2009, p. 17).

É preciso entender que a pesquisa sobre a prática docente necessita da pesquisa como ciência. Ou seja, pesquisa é pesquisa em ambas as situações. A questão talvez seja que o objeto de investigação e a finalidade da pesquisa sejam outras. Porém é preciso entender que não se ressignifica substancialmente a prática docente somente observando, pensando e registrando-se sobre ela, sem um processo estruturado que permite conhecer com profundidade a partir de um método que possibilite uma compreensão do objeto investigado. Para Silva (2008), é 
fundamental que o conhecimento se organize a partir da reflexão-crítica-investigativa, com critérios que garantam o rigor científico.

Outros cinco mestres entrevistados demonstraram ter uma concepção ampla de pesquisa e consideram que um professor passa a ser professor-pesquisador quando desenvolve atividades específicas em sala de aula com os seus alunos ou em atividades fora do espaço de docência, mantendo-se atualizado. Dentre as respostas destacamos:

Professor 2: É um professor que está sempre em busca de algo que venha complementar o seu saber docente. [...] O ser curioso.

Professor 3: É aquela atividade que se estende além da atividade pedagógica meramente de sala de aula."

Professor 5: Professor-pesquisador na realidade é todo aquele professor que se mantém atualizado. [...] todo professor que vai para a sala de aula necessariamente tem que antes de mais nada se preparar.

Tais respostas nos levam a inferir que para tais professores qualquer situação é valida como pesquisa, o esforço por encontrar um objeto, a busca por uma informação ou determinado conhecimento, podendo se tornar um mero esforço mental, uma ação deslocada no processo pedagógico. Por serem professores mestres que vivenciaram um processo de formação stricto sensu, indagamo-nos acerca da influência dessa formação na compreensão de tal conceito. Conforme já apontado na pesquisa realizada por Rausch e Schroeder (2010), é preciso avançar para uma concepção de pesquisa como uma investigação sistemática crítica e autocrítica que requer métodos apropriados visando ao avanço do conhecimento, e um entendimento de professor-pesquisador como aquele que pesquisa seus problemas do cotidiano docente visando ao desenvolvimento de uma prática pedagógica que promova o sucesso na aprendizagem dos alunos.

Um dos professores entrevistados apresentou uma distinção entre a atividade do professor e a atividade do pesquisador de maneira enfática: para tal entrevistado, o professor seria aquele que se forma e 
dedica-se à docência, enquanto o professor pesquisador não se prende à sala de aula, estando mais ligado às atividades científicas, à pesquisa de campo, aos seminários.

Professor 6: Acho que podemos distinguir dois tipos de professores. Tem o professor que se forma especificamente para atuar em sala de aula [...]. O pesquisador, ele seria mais um professor que se prepara para a prática da pesquisa contínua. Ele faz mestrado, doutorado, pós-doutorado, e fica não apenas com alunos em sala de aula, mas ele vai para campo, vai a estudos, seminários e tudo mais. [...] Ele trabalha com mestrado, trabalha com alguns alunos, mas sempre com a linha de pesquisa e não a linha de ensino, especificamente em sala de aula.

Esse professor ilustra outro tipo de conceito, que considera o professor-pesquisador como alguém que obrigatoriamente não se prende à atuação em sala de aula, estando mais preocupado com a atividade propriamente de pesquisa científica nos moldes da academia em detrimento da docência. Conceito este que denota certa confusão entre a ideia de professor-pesquisador e a ideia de pesquisador-professor. Este, sim, dedica-se, em primeiro lugar à sua atividade de pesquisa, embora tenha formação como docente.

\section{O professor-pesquisador no contexto docente da educação básica}

Em determinado momento da entrevista indagamos se os sujeitos investigados se consideravam professores pesquisadores e quais eram suas justificativas para se caracterizarem como tal. No que concerne à primeira indagação, três deles consideram-se professores pesquisadores; três declararam se considerar 'em parte'; um afirmou não se considerar; e outro não soube se posicionar. Dentre as principais justificativas apresentadas pelos entrevistados que se consideram professores-pesquisadores, mencionaram: 
Professor 5: Sim, eu me considero um professor-pesquisador, inclusive eu desenvolvo e coordeno projetos de pesquisa. [...] A utilização da pesquisa como ferramenta didática, para ser utilizada em sala de aula, para levar o aluno compreender aquilo que está nos livros, é extremamente possivel.

Professor 7: Sim, eu me considero. Hoje eu não tenho projetos de pesquisa, é difícil de a gente desenvolver nesse sentido as pesquisas. O que eu faço, eu observo empiricamente, observo e tento elaborar as questões que são de observações, de forma reflexiva. Eu internalizo, elaboro estas questões, reflito e tento resolver de alguma forma.

Professor 8: Sim, eu falo isso porque eu tenho realizado várias experiências na minha prática cotidiana. A minha dissertação de mestrado foi a partir de uma prática de pesquisa realizada na minha sala com os meus alunos.

\section{Os professores que se consideram professores-pesquisadores "em parte" justificaram:}

Professor 1: Em parte. Porque eu consigo realizar individualmente, para mim, para enriquecimento da minha ação pedagógica algumas investigações informais com as minhas crianças. E isso é em parte sim. E em parte não, isso não está sendo sistematizado, não está sendo divulgado. É uma coisa mais individualizada.

Professor 3: Em partes sim, em partes não. Eu vejo que para você ser um professor-pesquisador demanda tempo. Isso significa que para você ter esse tempo você não poderia ter uma carga horária muito carregada. [...] Eu acho que isso é um dos fatores que prejudica muito o professor poder ser professor-pesquisador.

Professor 6: [...] partir do momento que eu preparo um conteúdo novo, eu procuro ver o que existe de novo nessa situação, dentro do tempo disponivel, eu vejo na internet, novos livros e tudo o mais. Mas dizer que dá para fazer uma pesquisa mais profunda, eu diria que não. Não há esse tempo. 
Um entrevistado (Professor 4) afirmou não ser professor-pesquisador e justificou Eu não me considero uma professora-pesquisadora porque eu não trabalho com pesquisa. A gente não tem tempo para pesquisa. Eu que sou professora da rede municipal, trabalho até 40 horas por semana[...].

As respostas dadas pelos professores nos remetem a perceber a dificuldade enfrentada por eles para tornarem-se professores-pesquisadores e de que a pesquisa propriamente dita ainda não acontece na educação básica. O que realizam em sala de aula são atividades de cunho pedagógico, educativo. Sem desconsiderar esse processo que também é fundamental no processo educacional, e que pode tornar-se uma iniciação à pesquisa como princípio metodológico do ensino para os alunos da educação básica, como defende Demo (1991), tal processo só não caracteriza o professor-pesquisador.

Outras respostas nos remetem a ideia de pesquisa como atitude reflexiva, confundindo professor-pesquisador com professor-reflexivo. Vários autores defendem a reflexividade como um processo fundamental na formação e atuação docente, dentre eles destacamos Schön (1987) e Alarcão (2004), em que o professor reflita sobre sua ação docente e seus saberes, objetivando ressignificar permanentemente o processo ensino-aprendizagem, tornando-o mais significativo para ele e para seus alunos. Entretanto,

a reflexão da prática é insuficiente quando não se dispõe de recursos metodológicos e teóricos que permitam uma nova práxis profissional. Nesse sentido a teoria desempenha um papel essencial em sua relação dialética com a prática, sendo mais produtiva na medida em que se orienta em novas referências teóricas do saber científico, na medida em que se realiza com métodos sistematizados (atitude de pesquisa) que levam a uma posição crítica da prática em questão (RAMALHO; NUÑEZ; GAUTHIER, 2003, p. 26).

É por isso que defendemos a necessidade de o professor ser reflexivopesquisador, bem como pelo desenvolvimento de uma postura reflexiva-investigativa na formação de professores (RAUSCH, 2008). Fiorentini (2004) também corrobora com essa ideia quando destaca que toda a prática investigativa pressupõe e realiza-se mediante um processo reflexivo, e neste sentido, toda a pesquisa é uma forma especial de reflexão. Porém, nem toda reflexão é necessariamente 
pesquisa e ambas, pesquisa e reflexão, são na verdade, duas práticas distintas, complementares e essenciais no processo de formação docente.

Cruz e Lüdke (2005) argumentam que articular o ensino e a pesquisa no trabalho do professor da educação básica é algo que há muito tempo vem merecendo atenção dos profissionais que se dedicam a este estudo. A investigação das autoras revelou que a pesquisa deveria ser a base de sustentação do ensino básico, só que para isso, seria preciso uma reforma no desenvolvimento dos professores como pesquisadores de suas próprias práticas, e a partir daí, inserir a pesquisa no seu trabalho de sala de aula, visando o processo de ensino-aprendizagem dos alunos.

Quando defendemos a pesquisa de professores da educação básica, é entendida como um processo de se fazer ciência, e em se tratando de professor-pesquisador, um processo de se fazer ciência acerca da docência. Mas para isso, conforme argumenta Silva (2008), acompanhada da discussão epistemológica e a formação é preciso criar políticas de pesquisa e discutir as questões de carreira e material escolar, incentivando-se a profissionalização e a profissionalidade docente. A profissionalização tem a ver com os processos de formação no âmbito das licenciaturas e formação continuada, das competências e das habilidades profissionais, do salário e da carreira. A profissionalidade volta-se a desempenhar o ofício docente de forma competente e responsável, assumindo um compromisso social, político e ético com o trabalho.

Brzezinski (2007) também destaca que faltam estudos sobre políticas de formação e profissionalização docente no país. Alerta que se tem estudado a formação docente, porém os enfoques apontados encontram-se alijados diante da pouca compreensão das condições de trabalho, carreira e políticas voltadas ao apoio ao trabalho e as possibilidades dos docentes para que possa ocorrer a pesquisa na educação básica.

\section{A contribuição do mestrado à formação do professor-pesquisador}

A pós-graduação em nível stricto sensu no Brasil, organizada em cursos de mestrado e doutorado, vem expandindo-se e firmando-se como 
referência no desenvolvimento da pesquisa científica. Cada vez mais cresce a busca por essa formação, entretanto, como afirma Velloso (2004), o principal destino profissional dos que se formam mestres e doutores no país é a universidade. Atualmente, por meio da busca dos sujeitos dessa pesquisa, podemos inferir que até existem profissionais trabalhando nas redes de ensino da educação básica, porém em cargos de direção e coordenação nas secretarias de educação e alguns em escolas. Isso corrobora com o nosso estranhamento por encontrar no município de Blumenau tão poucos mestres atuando na sala de aula da educação básica.

Acerca da última questão sobre se os professores consideram o mestrado como propulsor de uma postura investigativa em sua docência, encontra-se o maior índice de concordância entre os sujeitos. Dos oito entrevistados, sete responderam que sim e enfatizaram muito a importância do mestrado na atividade docente. O Professor 1 destacou: Foi significativo e foi realmente transformador, porque além de eu conseguir perceber essas questões que eu não percebia, eu aprendi muito sobre como ler, sobre como escrever, sobre como pesquisar. Enquanto sujeito isso foi muito significativo para mim.

Observamos que os professores consideram que o mestrado transformou a sua maneira de dar aula, de aprender e ensinar. O Professor 8 defendeu que o mestrado foi fundamental à sua formação:

Professor 8: Foi um divisor de águas na minha postura de professor e de pesquisador. É muito bom olhar para trás e ver que realmente o mestrado me transformou. [...] ele me transformou num profissional bem melhor do que eu era. E é interessante que muitas vezes a gente peca como profissional por ignorância mesmo. Não é nem por má vontade, por falta de dedicação, é por falta de conhecimento mesmo. Por falta de saber o que está sendo produzido aí fora, por não ter conhecimento de coisas inovadoras, de coisas que podem proporcionar uma prática mais efetiva. E nesse sentido o mestrado foi fundamental principalmente porque ele me fez refletir a minha prática. $\mathrm{Me}$ fez pensar naquilo que eu estava fazendo e como eu poderia melhorar. Então quando eu desenvolvi a minha pesquisa, a minha dissertação, eu fiz justamente com esse intuito de estar me analisando e buscando o que tinha de positivo e de negativo e o que poderia melhorar. E com certeza eu consigo 
enxergar com bastante propriedade hoje a forma como eu atuava, a forma como eu atuo e a evolução que eu tive. Então foi muito importante mesmo.

Apenas um dos entrevistados destacou que o mestrado não contribuiu muito à sua formação docente. Sua justificativa é que ele já possuía uma postura investigativa e desenvolvia projetos de pesquisa anteriormente ao mestrado, e que este muito pouco modificou a sua prática. Quando questionado se julgava o mestrado como propulsor de uma postura mais investigativa na sua docência, o Professor 3 respondeu: Não, porque eu já realizava este trabalho antes de ingressar no mestrado. [...] O mestrado vem mostrar metodologias diferentes, mostra outros caminhos além daquilo que eu já fazia.

Esse professor, diferente dos outros entrevistados que iniciaram seus processos como pesquisadores no mestrado, teve oportunidade de se inserir no contexto da pesquisa já nas licenciaturas, participando de programas de iniciação científica e realizando o Trabalho de Conclusão de Curso (TCC) nos moldes da pesquisa científica. Tal depoimento reitera os resultados apontados na tese de Rausch (2008) acerca da relevância de se inserir já nas licenciaturas diferentes possibilidades de os futuros professores vivenciarem concretamente processos de pesquisas. Tais processos contribuem consideravelmente com uma possível postura reflexiva e investigativa dos professores.

\section{Considerações finais}

No nosso entender, é fundamental que os professores da educação básica sejam promotores de conhecimento e realizem pesquisas no contexto profissional docente, no intuito de avançarmos na qualidade educativa nesse nível de ensino. O desafio posto na atualidade é que seja professor e pesquisador simultaneamente, pois a pesquisa lhe permitirá pensar e agir de forma especial, diferenciada e fundamentada diante de sua profissão. Conforme destaca Silva (2008), a pesquisa em educação 
pode ser considerada uma forma de intervenção e mediação no processo de transformação social.

De um modo geral, os resultados apontaram diferentes percepções e ações dos professores diante da pesquisa na educação básica. Ficou evidenciada, nas respostas, a trajetória de vida e de formação de cada professor, que é única e singular. Os professores mestres evidenciaram também, de uma forma geral, a dificuldade que sentem em realizar pesquisas como professores da educação básica, ou seja, não conseguem ser professores e, ao mesmo tempo, pesquisadores. Esse trabalho, em grande parte, depende da formação que tiveram, das condições oferecidas pela escola e também da sua disponibilidade de tempo, que invariavelmente entre os nossos entrevistados, trabalham 40 horas semanais e em alguns casos ainda realizam atividades em outras profissões.

Não obstante, encontram-se algumas semelhanças entre os depoimentos dos professores, principalmente na questão que se refere à realização de atividades de pesquisa na escola, em sala de aula com os alunos, ou com outros docentes. O que realizam volta-se mais a algumas estratégias didáticas, como estudos, busca de informações e instrumentos para desenvolver seu trabalho docente do que um processo de pesquisa. A maioria dos professores demonstrou grande vontade e interesse em desenvolver pesquisas na escola, e consideram-se habilitados para tal. Porém manifestou estar impossibilitada a efetivá-la graças a uma série de fatores relacionados à estrutura física das escolas, à falta de tempo, à baixa remuneração, ao pouco incentivo e apoio por parte da rede municipal de ensino e da coordenação das escolas.

Essa realidade nos faz refletir que na literatura educacional há sim ênfase na necessidade de formar o professor-pesquisador, propondo que os professores se tornem pesquisadores de sua prática sendo produtores de conhecimentos. Entretanto, muitas vezes não se discute a trajetória de formação dos professores, as condições de trabalho e de carreira e até mesmo dos recursos financeiros e de infraestrutura necessários para o professor de educação básica conseguir produzir pesquisa. 


\section{Referências}

ALARCÃO, I. Professores reflexivos em uma escola reflexiva. São Paulo: Cortez, 2004.

BARDIN, L. Análise de conteúdo. Lisboa: Edições 70, 1977.

BRZEZINSKI, I. GT 8: a pesquisa sobre formação de profissionais da educação em 25 anos de história. In: REUNIÃO ANUAL DA ASSOCIAÇÃO NACIONAL DE PÓS-GRADUAÇÃO E PESQUISA EM EDUCAÇÃO - ANPED, 30., 2007, Caxambu. Anais... Caxambu: ANPED, 2007. p. 1-15.

CRUZ, G. B. da; LÜDKE, M. Aproximando universidade e escola de educação básica pela pesquisa. Cadernos de Pesquisa, v. 125, p. 81-109, maio./ago. 2005.

DEMO, P. Pesquisa: princípio científico e educativo. São Paulo: Cortez, 1991.

ESTEBAN, T. M.; ZACUR, A. (Org.). Professora-pesquisadora uma práxis em construção. Rio de Janeiro: DP\&A, 2002.

FIORENTINI, D. A didática e a prática de ensino mediada pela investigação sobre a prática. In: ROMANOWSKI, J.; MARTINS, P.; JUNQUEIRA, S. (Org.). Conhecimento local e conhecimento universal: pesquisa, didática e ação docente. Curitiba: ENDIPE: Champagnat, 2004. p. 243-258.

LÜDKE, M. (Coord.). 0 que conta como pesquisa? São Paulo: Cortez, 2009.

LÜDKE, M. Convergências e tensões reveladas por um programa de pesquisas sobre formação docente. In: DALBEN, A. et al. (Org.). Convergências e tensões no campo da formação e do trabalho docente: didática, formação de professores e trabalho docente. Belo Horizonte: ENDIPE: Autêntica, 2010. p. 260-272.

RAMALHO, B. L.; NUÑEZ, I. B.; GAUTHIER, C. Formar o professor - profissionalizar o ensino: perspectivas e desafios. Porto Alegre: Sulina, 2003.

RAUSCH, R. B. A reflexividade promovida pela pesquisa na formação inicial de professores. 2008. Tese (Doutorado em Educação) - Universidade Estadual de Campinas, Campinas, 2008. 
RAUSCH, R. B.; SCHROEDER, S. L. A inserção da pesquisa nas séries iniciais do ensino fundamental. Atos de Pesquisa em Educação, v. 5, n. 3, p. 315-337, 2010. SCHÖN, D. A. Educando o profissional reflexivo. Porto Alegre: Artes Médicas, 1987. SILVA, K. A. P. Professores com formação stricto sensu e o desenvolvimento da pesquisa na educação básica da rede pública de Goiânia: realidade, entraves e possibilidades. 2008. Tese (Doutorado em Educação) - Universidade Federal de Goiás, Goiânia, 2008.

VELLOSO, J. Mestres e doutores no país: destinos profissionais e políticas de pós-graduação. Cadernos de Pesquisa, v. 34, n. 123, p. 583-611, set./dez. 2004. ZEICHNER, K. M. Uma agenda de pesquisa para a formação docente. Formação Docente, v. 1, n. 1, ago./dez. 2009.

Recebido: 28/04/2012

Received: 04/28/2012

Aprovado: 05/06/2012

Approved: 06/05/2012 